\title{
Numerical simulation of the orthogonal cutting, using the finite element method
}

\author{
Claudiu-Ionuț MALEA ${ }^{1,3}$ and Claudiu BĂDULESCU ${ }^{2}$ \\ ${ }^{1}$ University of Pitești, Faculty of Mechanics and Technology, Manufacturing and Industrial Management \\ Department, Târgul din Vale Street No.1, Romania \\ ${ }^{2}$ The Research Institute Dupuy de Lôme, UBS-UBO-ENSTA Bretagne-ENIB, UMR CNRS 6027, 2 , \\ François Verny Street, 29806 Brest Cedex 9, France \\ *Corresponding author e-mail: malea.claudiu@gmail.com
}

Article history

Received 03.09.2020

Accepted 17.10 .2020

DOI https://doi.org/10.26825/bup.ar.2020.007

\begin{abstract}
The purpose of this article is to create a simulation model for an orthogonal cutting process, using Abaqus which is a finite element analysis software. Thus, a two-dimensional model is defined, describing the shape of the semi-finished product and the cutting tool used, as well as the material parameters needed to be correctly defined and validated. The JohnsonCook material model and degradation model, the model of friction coefficient are defined, as well as the obtaining of test parameters by a shear test to obtain useful parameters. The results are focused on the study of the forces that appear during the process of removing the metallic material.
\end{abstract}

Keywords: orthogonal cutting, Abaqus, finite element method, shear test

\section{Introduction}

During the mechanical process of removing the material, various phenomena occur, which can be anticipated to some extent. The orientation, which the researches in the field of cutting processing [1, $2,3]$ and not only, is to determine the best processing conditions and the well-chosen geometries, in order to have the most efficient manufacturing processes at a lower cost. Experimental research has high costs and high execution time, and simple analytical calculation methods do not explain very well all the phenomena that occur during processing, so analysis with the finite element method is necessary.

A simulation model for the mechanical cutting processes must satisfy all the complex thermomechanical phenomena that appear, inside the cutting tool, but also in the semi-fabricated one. At the same time, it should be a simpler model, to facilitate a shorter computation time. Within a simulation model with Abaqus, it must be described: the material model used, the material discretization, the contact properties, the boundary conditions, the applied forces.

Various characteristics and curves can be obtained from the simulations, such as the cutting forces, the temperatures released, the chips shapes, depending on the various parameters, such as the chip thickness chip, the clearance angle, the friction coefficient, radius from the tip of the tool, without performing any experiments.

\section{Literature review}


Johnson and Cook developed a material model, where the equivalent tension is formulated according to the deformation speed and temperature, this model is established with an equation (2.1), which describes viscous plastic behavior, as follows $[1,2]$ :

$$
\sigma_{\mathrm{JC}}=\left(\mathrm{A}+\mathrm{B} \cdot\left(\bar{\varepsilon}^{\mathrm{pl}}\right)^{\mathrm{n}}\right)\left(1+\mathrm{C} \cdot \ln \frac{\mathrm{e}^{\mathrm{dl}}}{\mathrm{E}_{0}^{\mathrm{d}}}\right)\left(1-\left(\frac{\mathrm{T}-\mathrm{T}_{0}}{\mathrm{~T}_{\mathrm{m}}-\mathrm{T}_{0}}\right)^{\mathrm{m}}\right)
$$

where: $-\sigma_{\mathrm{JC}}$ is the equivalent stress Johnson-Cook;

- A is the elasticity limit of the material;

- B, C, $\mathrm{n}$ și $\mathrm{m}$ are the parameters of the material model;

- $\bar{\varepsilon}^{\mathrm{pl}}$ is the equivalent strain;

- ${ }^{a l}$ is the rate of equivalent strain.

The damage model of the chip is used together with the Johnson-Cook material, to determine the initiation of the cut. It has the following equation (2.2) [1]:

$$
\bar{\varepsilon}_{\mathrm{f}}^{\mathrm{pl}}=\left(\mathrm{D}_{1}+\mathrm{D}_{2}+\varepsilon^{\mathrm{D}_{3} \cdot \eta}\right)\left(1+\mathrm{D}_{4} \cdot \ln \frac{\frac{\mathrm{E}^{\mathrm{l}}}{\mathrm{d}}}{\mathrm{E}_{0}}\right)\left(1-\mathrm{D}_{5} \frac{\mathrm{T}-\mathrm{T}_{0}}{\mathrm{~T}_{\mathrm{m}}-\mathrm{T}_{0}}\right)
$$

where: - $\mathrm{D}_{1}, \mathrm{D}_{2}, \mathrm{D}_{3}, \mathrm{D}_{4}, \mathrm{D}_{5}$ material parameters;

In the shear zone, once the degradation criterion is reached, the strain-stress curve decreases to a minimum value, which is called the degradation evolution, described by the formula (2.3):

$$
\sigma_{\mathrm{D}}=(1-\mathrm{d}) \cdot \sigma_{\mathrm{JC}}
$$

where: $-\sigma_{\mathrm{D}}$, the degradation evolution;

The law of evolution of degradation is expressed as a function that depends on the equivalent plastic displacement $\overline{\mathrm{u}}^{\mathrm{pl}}$. Before initiation of cutting $=0$, and after initiation $=\mathrm{L} \mathrm{d}^{\mathrm{t}}$. Thus a linear evolution of $\mathrm{d}$ is required depending on $\overline{\mathrm{u}}^{\mathrm{pl}}$, as in the equation (2.4):

$$
\begin{aligned}
& \mathrm{d}=\mathrm{d}\left(\overline{\mathrm{u}}^{\mathrm{pl}}\right) \\
& w^{\mathrm{el}}=\mathrm{L} \\
& \&=\frac{L E^{\mathrm{pl}}}{\overline{\mathrm{u}}_{\mathrm{f}}^{\mathrm{pl}}}=\frac{\overline{\mathrm{u}}_{\mathrm{f}}^{\mathrm{pl}}}{\bar{p}^{\mathrm{l}}}
\end{aligned}
$$

Equivalent plastic strain $\bar{\varepsilon}_{0}^{\mathrm{pl}}$, depends on two parameters: the relative shear tension $\theta_{\mathrm{s}}$, expressed with the equation (2.5) and the equivalent deformation speed ${ }^{1}$ [5]:

$$
\theta_{\mathrm{s}}=\frac{1-\mathrm{k}_{\mathrm{s}} \eta}{\phi}
$$

where: - $\mathrm{k}_{\mathrm{s}}$ is a material parameter;

$-\phi$ is the ratio between the maximum shear strain and the equivalent strain (von Mises).

To describe the part-tool interface, a model of the friction coefficient with a temperature-dependent evolution is used, as in the equation (2.6) [1]:

$$
\begin{cases}\mu=\mu_{0}, & \mathrm{~T}<\mathrm{T}_{\mathrm{r}} \\ \mu=\mu_{0} \cdot\left(1-\left(\frac{\mathrm{T}-\mathrm{T}_{\mathrm{r}}}{\mathrm{T}_{\mathrm{m}}-\mathrm{T}_{\mathrm{r}}}\right)^{\mathrm{m}_{\mathrm{r}}}\right), & \mathrm{T} \geq \mathrm{T}_{\mathrm{r}}\end{cases}
$$

where: - $\mu$ is friction coefficient with a temperature dependent evolution;

- $\mu_{0}$ is the initial friction coefficient at ambient temperature;

- $\mathrm{T}$ is the evolution of temperature; 
$-\mathrm{T}_{\mathrm{r}}$ and $\mathrm{m}_{\mathrm{r}}$ are the material parameters that will be calibrated using the apparent friction coefficients and by comparing the forces determined experimentally.

- $\mathrm{T}_{\mathrm{m}}$ is the melting temperature of the material.

In the description of the cutting model, it is necessary to draw the equivalent strain-stress curve, $\bar{\sigma}-\bar{\varepsilon}$, used to obtain the value of the degradation evolution and for the relative shear tension. The plot of the curve is performed using the von Mises equivalent strain and stress equations [5], from which it results, for a shear application, the equations (2.7) and (2.8):

$$
\begin{aligned}
& \bar{\sigma}=\sqrt{3} \cdot \sigma_{12} \\
& \bar{\varepsilon}=\frac{2}{\sqrt{3}} \cdot \varepsilon_{12}
\end{aligned}
$$

\section{Research method}

The geometrical model is described in Figure 1, which represents a classic diagram of the orthogonal cutting process, with a chip height of $0.1[\mathrm{~mm}]$. A degradation zone of $5.5[\mu \mathrm{m}]$, depending on the tip tool radius [6] of $4.8[\mu \mathrm{m}]$, is required.

The construction of the tool is made with the property of being non-deformable, and the workpiece will be fixed throughout the entire process, the movement being executed by the tool.

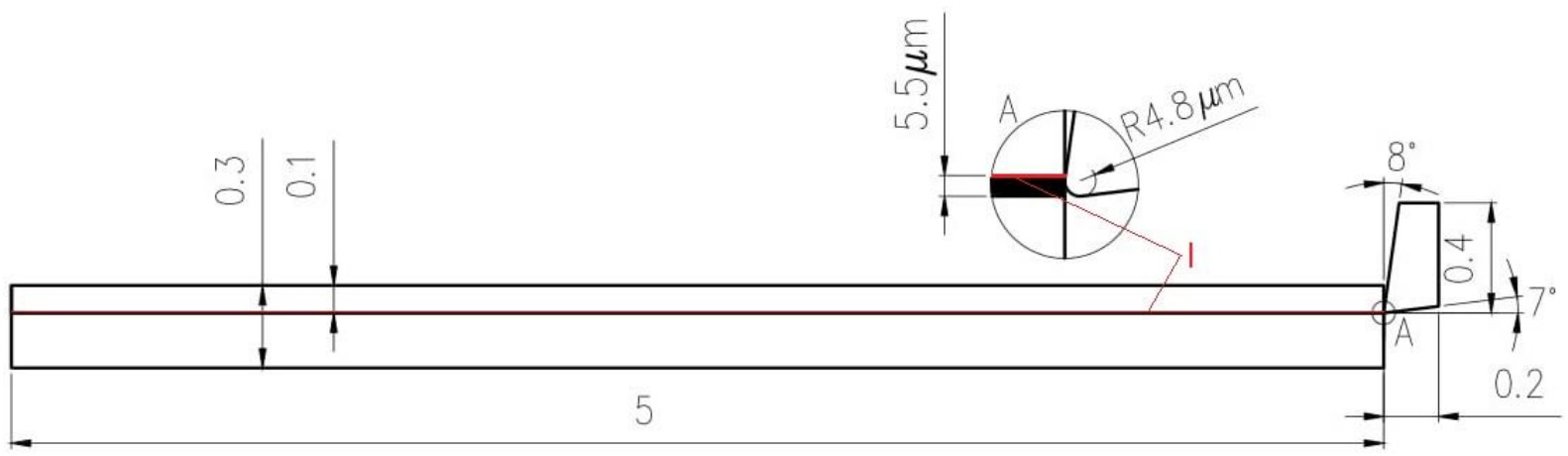

Figure 1. Classic diagram of the orthogonal cutting process

For the correct definition of the model it is necessary to obtain the material parameters.

The chemical characteristics are recorded in Table 1, and respectively the elastic behavior at ambient temperature, in Table 2, for later introduction in Abaqus, for NiCr19Nb5Mo3 alloy.

Table 1. The physical properties of the NiCr19Nb5Mo3 alloy

\begin{tabular}{cc}
\hline Density $\left[\mathrm{kg} / \mathrm{m}^{3}\right]$ & 8391,6 \\
\hline Thermal conductivity $[\mathrm{W} / \mathrm{mK}]$ & 11,5 \\
\hline Specific heat $[\mathrm{J} / \mathrm{kgK}]$ & 460 \\
\hline The transformation fraction of mechanical deformation into heat & 0,9 \\
\hline
\end{tabular}

Table 2. The elasticity of the NiCr19Nb5Mo3 alloy

\begin{tabular}{c|c|c} 
Temperature $\left[{ }^{\circ} \mathrm{C}\right]$ & Modulus of elasticity [MPa] & Poisson coefficient \\
\hline 25 & 200000 & 0.294
\end{tabular}

The material parameters are used to describe the plasticity, Johnson-Cook and the degradation parameters Johnson-Cook [1], obtained with equations (2.1) and (2.2), being registered in Tables 3 and 4. 
Table 3. Johnosn-Cook material parameters for the NiCr19Nb5Mo3 alloy [1]

\begin{tabular}{c|c|c|c|c|c|c|c}
$\begin{array}{c}\mathrm{A} \\
{[\mathrm{MPa}]}\end{array}$ & $\begin{array}{c}\mathrm{B} \\
{[\mathrm{Pa}]}\end{array}$ & $\mathrm{C}$ & $\mathrm{n}$ & $\mathrm{M}$ & $\begin{array}{c}\mathrm{\&} \\
{\left[\begin{array}{c}\mathrm{N} \\
{\left[\mathrm{s}^{-1}\right]}\end{array}\right.}\end{array}$ & $\begin{array}{c}\mathrm{T}_{\mathrm{m}} \\
{\left[{ }^{\circ} \mathrm{C}\right]}\end{array}$ & $\begin{array}{c}\mathrm{T}_{0} \\
{\left[{ }^{\circ} \mathrm{C}\right]}\end{array}$ \\
\hline 1262 & 1354 & 0.5 & 0.006 & 1.08 & 0.001 & 1340 & 250
\end{tabular}

Table 4. Johnson-Cook degradation parameters for the NiCr19Nb5Mo3 alloy [1]

\begin{tabular}{c|c|c|c|c|c|c}
$\mathrm{D}_{1}$ & $\mathrm{D}_{2}$ & $\mathrm{D}_{3}$ & $\mathrm{D}_{4}$ & $\mathrm{D}_{5}$ & $\eta$ & $\overline{\mathrm{u}}^{\mathrm{pl}}$ \\
\hline 0.4058 & 0.75 & 1.45 & 0.04 & 0.89 & 0.33 & 0.0001649
\end{tabular}

It is necessary to obtain the shear properties of NiCr19Nb5Mo3 alloy, so a model made by Iosipescu (1967) is required, as in Figure 2 a) and developed by other researchers [7,8], in which a pure shear state is achieved in the area, requesting the specimen by loading it with a radial force. In the absence of the necessary equipment to perform this test, a simplified Abaqus model is made, as in Figure 2 b), to obtain the desired parameters. The model takes the parameters from tables $1,2,3$ and 4 . The size of the discretization element will have the same value as the one used in the description of the orthogonal cutting application $(\mathrm{L}=0.02[\mathrm{~mm}])$, as well as the loading force corresponding to the cutting speed of $20[\mathrm{~m} / \mathrm{min}]$, figure $3.2 \mathrm{c})$. This is necessary to determine the parameters of equivalent plastic displacement $\overline{\mathrm{u}}^{\mathrm{pl}}$ and the relative shear tension $\theta_{\mathrm{S}}$.

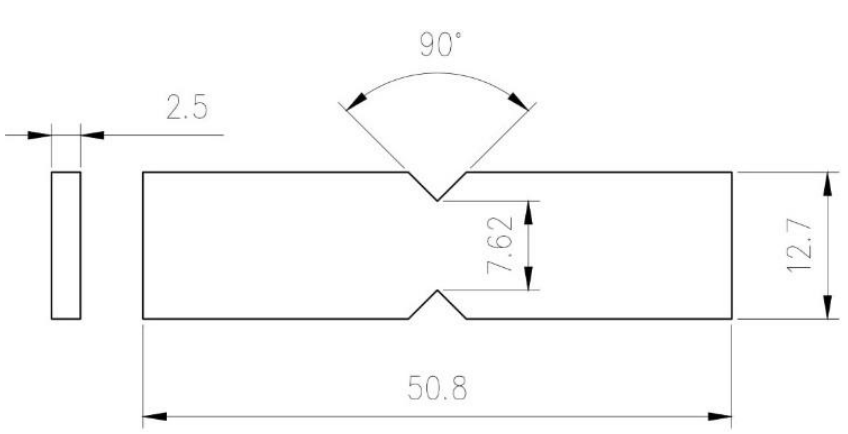

a)

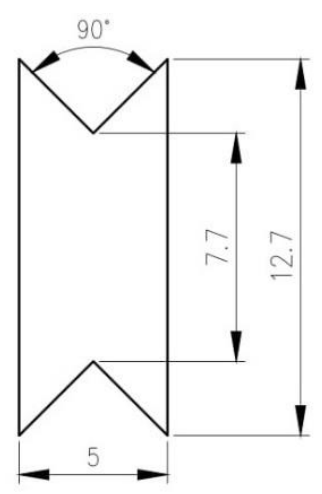

b)

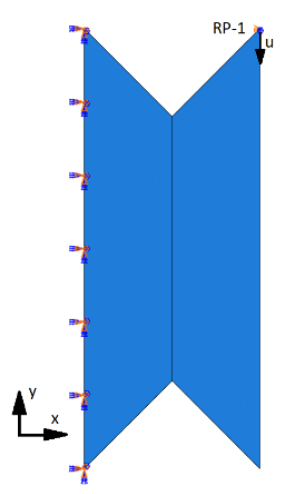

c)

Figure 2. The shear model described by Iosipescu

Following the request and measurement of the areas indicated in figure 3.3, the force-displacement, strain-stress shear curves are drawn $\sigma_{12}-\varepsilon_{12}$, respectively the equivalent strain-stress curve $\bar{\sigma}-\bar{\varepsilon}$, which is of interest for obtaining the desired parameters, with equations (2.7) and (2.8), as can be seen in figure 4.

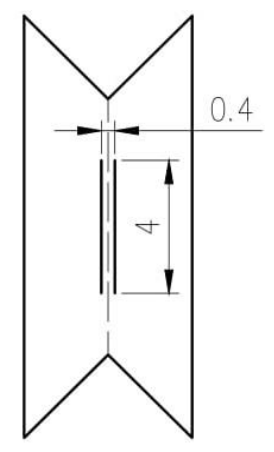

Figure 3. Zones for measuring displacements and forces

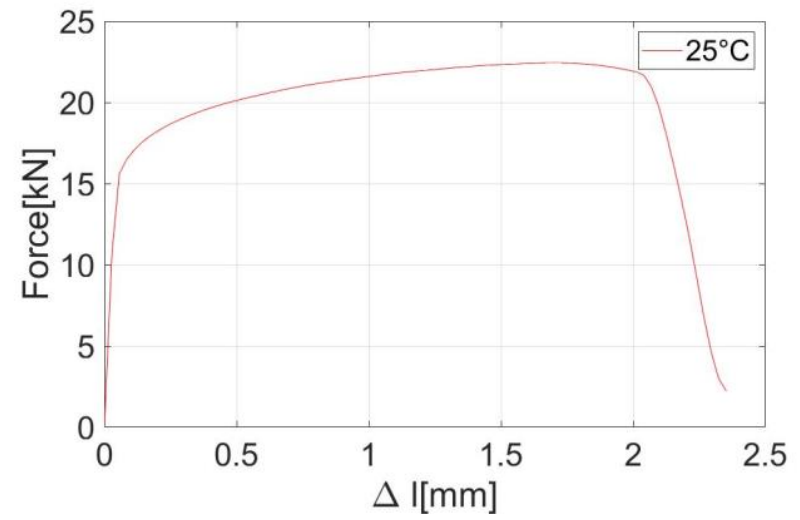

Figure 4. Equivalent strain-stress curve 
For the deterioration model in this type of analysis, some data extracted from the equivalent strainstress curve, figure 3.4 , at $25^{\circ} \mathrm{C}$, the final plastic deformation, are required $\bar{\varepsilon}_{\mathrm{f}}^{\mathrm{pl}}=0,76$ (figura 2.2), respectively the evolution of the degradation obtained by the formula (2.4), where:

$$
\overline{\mathrm{u}}^{\mathrm{pl}}=\mathrm{L} \mathrm{E}^{\mathrm{l}}=\mathrm{L}\left(\mathrm{E}_{\mathrm{f}}^{\mathrm{g} \mathrm{P}^{\mathrm{l}}}-\mathrm{E}_{0}^{\mathrm{gl}}\right)=0,02(0,76-0,52)=0,0048[\mathrm{~mm}]
$$

The value of the initial strain rate is selected from the table $3.4, \quad \underset{\delta}{\mathrm{E}}=0,001\left[\mathrm{~s}^{-1}\right]$. And for the relative shear tension, from equation $(2.5)$, for $\mathrm{k}_{\mathrm{s}}=0$, it turns out that:

$$
\theta_{\mathrm{s}}=\frac{1-\mathrm{k}_{\mathrm{s}} \eta}{\phi}=\frac{1-0 \cdot \eta}{\frac{\tau_{\max }}{\bar{\sigma}}}=\frac{1}{\frac{\sigma_{12}}{\sqrt{3} \cdot \sigma_{12}}}=\sqrt{3}
$$

For analysis, the material will be defined with area without degradation and zone with degradation, represented by the height of $5,5[\mu \mathrm{m}]$.

For the model in Figure 1, a discretization distribution is established, for the part within the simulation, where an element size of $\mathrm{L}=0.02[\mathrm{~mm}]$ is chosen, with 5 elements on the chip height, for the degraded area one element. This form of discretization is geometrized, to perform a relatively fast calculation, but also to match the results with those obtained experimentally. It is required a condition of restraint in the left and bottom edge of the workpiece, by eliminating the three degrees of freedom, present in the plane deformations. The cutting speed of $20[\mathrm{~m} / \mathrm{min}]$ is required and in the units imposed in Abaqus, of $3.3[\mathrm{~m} / \mathrm{s}]$, in the direction of movement of the tool.

There are two types of interactions that will occur during the cut:

a) The definition of the contact properties between the part and the tool is based on the definition of the friction coefficient, $\mu$, using the model in equation (2.6), where the unknown parameters are found in table 5.;

b) Avoiding the splitting of the chip is achieved by imposing the selfcontact interaction.

A comparison is made with the

Table 5. Parameters for the model of the coefficient of friction of the $\mathrm{NiCr} 19 \mathrm{Nb} 5 \mathrm{Mo} 3$ alloy [1]

\begin{tabular}{c|c|c}
\multicolumn{3}{c}{ friction of the NiCr19Nb5Mo3 alloy [1] } \\
\hline$\mu_{0}$ & $\mathrm{~T}_{\mathrm{r}}$ & $\mathrm{m}_{\mathrm{r}}$ \\
\hline 0,36 & 660 & 0,55 \\
\hline
\end{tabular}
results obtained, at a speed of $20[\mathrm{~m} / \mathrm{min}]$, by the methods proposed with the results of specialized works [1]. Figure 5 shows that the results for the Johnson-Cook material model are close enough to say that the model is validated.

\section{Results}

After obtaining the result performed with Abaqus and validating it with an experimentally result in the specialized work [1], for a cutting speed of 20 [m/min], a parametric study is proposed for different variables in the system, as a result of which they observe the influences that they have during the orthogonal cutting processes.

The influence that the force has during the removal of the chip is studied, drawing the tendencies curves of the forces in the stability zones, for parameters such as the size of the discretization element $(\mathrm{L})$, the height of the chip $(\mathrm{h})$, the cutting speed $\left(\mathrm{v}_{\mathrm{c}}\right)$, the clearance angle $(\gamma)$, the coefficient of friction $(\mu)$

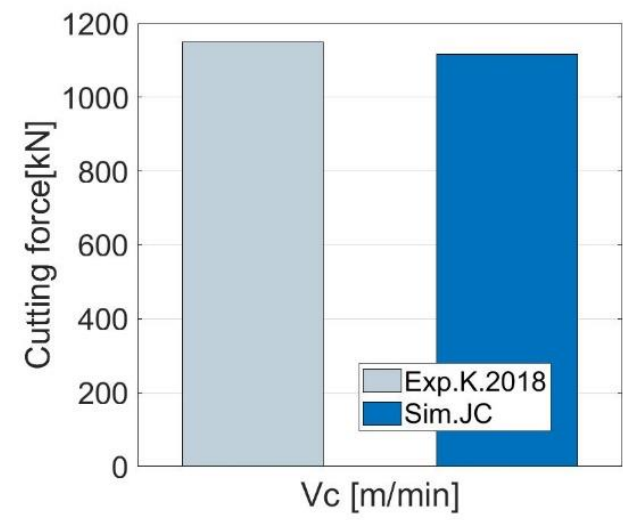

Figure 5. Comparing the results and the radius at the tip of the cutting tool $\left(\mathrm{r}_{\beta}\right)$, respectively, having the values for the validated model of: $\mathrm{L}=0.02[\mathrm{~mm}], \mathrm{h}=0.1[\mathrm{~mm}], \mathrm{v}_{\mathrm{c}}=20[\mathrm{~m} / \mathrm{min}], \gamma=8^{\circ}, \mu$ is described by the proposed friction coefficient model and $\mathrm{r}_{\beta}=4.8[\mu \mathrm{m}]$. 


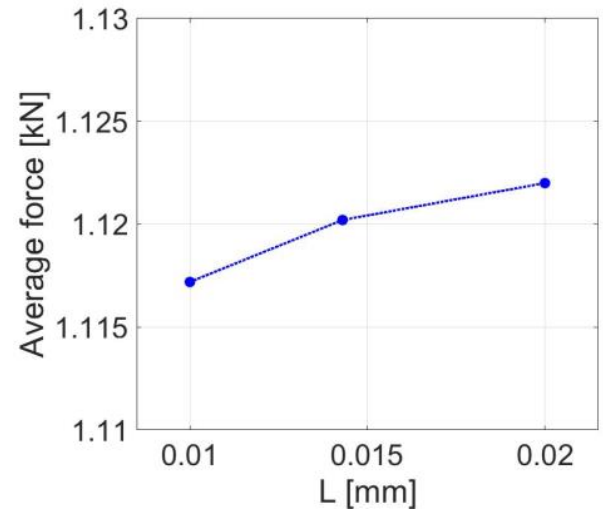

Figure 6. The tendency of the cutting force according to the size of the discretization element

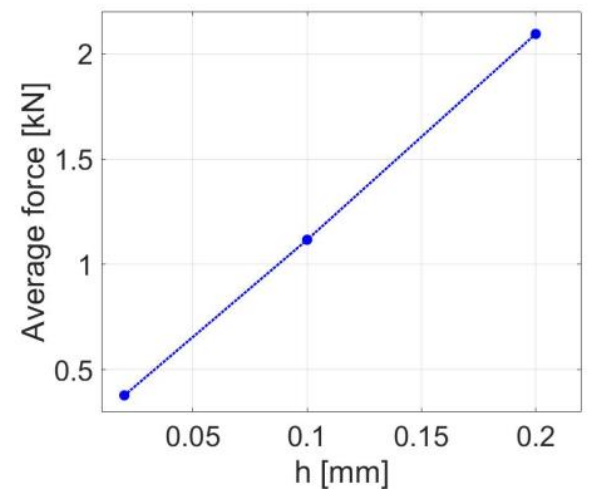

Figure 7. The tendency of the cutting force according to the height of the chip

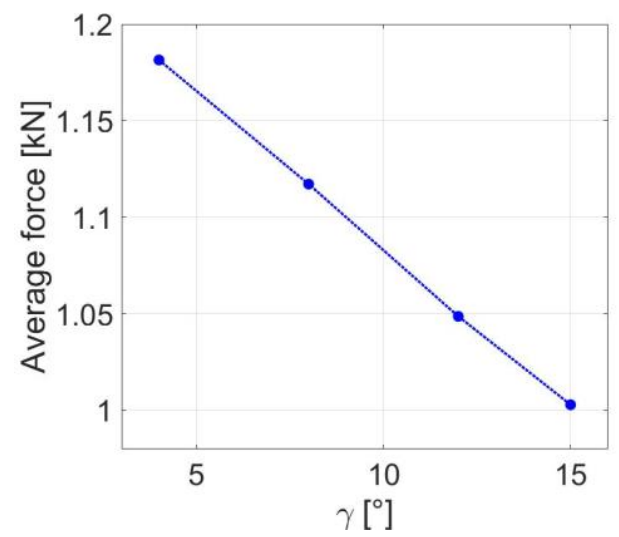

Figure 8. The tendency of the cutting force according to the clearance angle

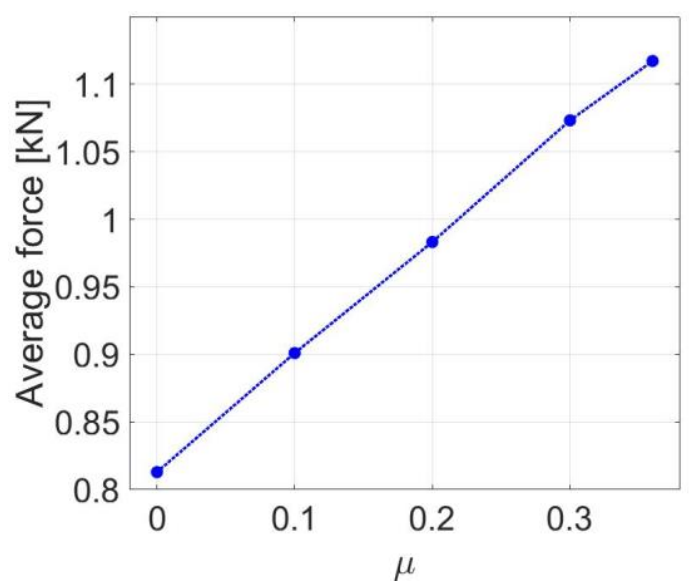

Figure 9. The tendency of the cutting force according to the coefficient of friction

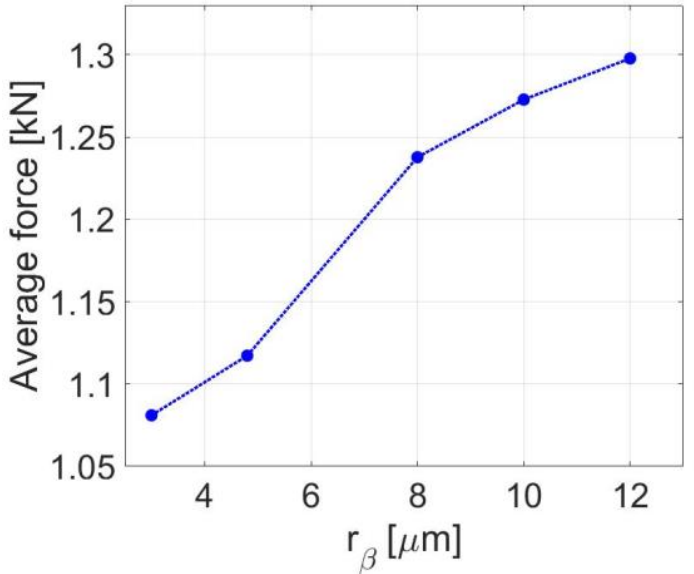

Figure 10. The tendency of the cutting force according to the radius of the cutting tool tip

In the curves in Figures 6, 7, 8, 9 and 10, we can see the average evolution of the force in the areas where the cutting becomes stable, after the chipping has been initiated.

In Figure 6 we can see how the size of the discretization element does not have a pronounced influence, this fact facilitating the calculation of the analysis of a future process, choosing the largest size of $0.02 \mathrm{~mm}$. The evolution in Figure 7 is obvious because for a larger size of the chip the friction force is higher, as well as the released chip. The larger the clearance angle, the faster the chip is 
removed, and the forces are smaller as shown in Figure 8. In Figure 9 the imposition of a higher friction coefficient leads to large forces because the friction force will have high values as well. The radius must as small as possible to facilitate the initiation of the formation of the chip, in other words, as higher the radius values will be the force will increase.

\section{Conclusions}

In this paper, a thermo-mechanical model of an orthogonal cutting process with a continuous formation of chips is presented. With this model, it can be extracted various parameters such as the cutting force.

During mechanical processing, numerous phenomena occur, which cannot be easily anticipated, the simulation being uncertain. For this, it is necessary to implement some parameters for which the phenomena appeared can be predicted, such as material model, contact conditions, correct distribution of the separation between the chip and the semi-product.

The imposition of a deterioration zone is necessary for the simulations, so the results can be conclusive, but this zone does not exist for physical applications.

As a perspective, it can study the influences that different material models have during mechanical machining. It is also possible to implement different models of friction coefficients and to study their influence, as well as to make 3D models, by which one can observe how the surface of the processed part is influenced.

\section{Acknowledgements}

This article presents some o the activities I have done at the Dupuy de Lôme Research Institute (IRDL) at ENSTA, Bretania, Brest in France, during the 4 month internship (April 1, 2019 - July 31, 2019).

\section{References}

[1] Klocke, F., Döbbeler, B., Peng, B. and Schneider S. A. M. (2018). 8th CIRP Conference on High Performance Cutting, Tool-based inverse determination of material model of Direct Aged Alloy 718 for FEM cutting simulation, 77, 54-57.

[2] Arrazola P. J., Özel T., Umbrello D., Davies M. et Jawahir I. S. (2013). CIRP Annals Manufacturing Technology. Recent advances in modelling of metal machining processes, 62, 695-718

[3] Liu G., Huang C., Su R., Özel T., Liu Y. et Xu L. (2019). International Journal of Mechanical Sciences. 3D FEM simulation of the turning process of stainless steel 17-4PH with differently texturized cutting tools, 155, 417-429.

[4] Dorogoy, A. et Rittel D. (2008, novembre). Society for Experimental Mechanics. Determination of the Johnson-Cook material parameters using the SCS specimen, 49, 881885.

[5] Hooputra, H., Gese H., Dell H. et Werner H. (2004). International Journal of Crashworthiness. A comprehensive failure model for crashworthiness simulation of aluminium extrusions, 9 , 449-463.

[6] Kalay, F. (2010, octobre). Simulation numérique de l'usinage Application à l'aluminium AU4G (A2024-T351), France

[7] He J., Chiang M. Y. M., McDonough W. et Huston D. L. (1990). Polymers Division, National Institute of Standards and Technology. Expreimental and theoretical evaluation of the Iosipescu shear for hybrid fiber composites. Ville: Gaithersburg, USA

[8] Bru T., Olsson R., Gutkin R. et Vyas G. M. (2017). Use of the Iosipescu test for the identification of shear damage evolution laws of on orthotropic composite. 174, 319-328. 